\title{
The Research on Seismic Response of Prestressed Concrete Flat Beam in Pseudo-dynamic Test
}

\author{
Feiyan Li \\ Xiamen University Tan Kah Kee College, Zhangzhou, Fujian, China, 363105 \\ Ify24@xujc.com
}

Keyword: prestressed concrete; flat-beam frame; seismic response; pseudo-dynamic test

\begin{abstract}
By carrying out pseudo-dynamic test on an unbonded and a bonded prestressed concrete flat beam separately, their dynamic properties and seismic responses can be learned; also seismic resistance can be compared. The test results show that framework with prestressed concrete flat beam has certain energy-absorbing capacity, and no matter bonded form or not it makes little influence on overall seismic performance and failure form. In addition, the beam-column strength ratio should be increased properly in design.
\end{abstract}

\section{Preface}

Due to reasonable structural design and convenient construction, floor system with prestressed concrete flat beam has highly potential on reducing floor height, saving cost and satisfying building requirement. In this paper, pseudo-dynamic experiment are carried out on an unbonded and a bonded prestressed concrete flat beam separately so that dynamic properties and seismic responses can be known, also their earthquake resistances are compared.

\section{Brief Introduction of Experiment[1][2][3]}

Design of test-pieces. These two frameworks with prestressed concrete flat beam are designed on the principle of 'strong columns and weak beams, strong joint and weak element', their geometric size, material and configuration of non-prestressed steel are all the same, modal scale both are 1:3. The cross section of frame columns are $250 \mathrm{~mm} * 350 \mathrm{~mm}$, the cross section of flat beams are $450 \mathrm{~mm} * 200 \mathrm{~mm}$. Non-prestressed reinforcements are HRB335, fy=300MPa, Es $=200 \mathrm{GPa}$, stirrups are HPB235, fy $=210 \mathrm{MPa}, \mathrm{Es}=210 \mathrm{GPa}$; Concrete intensive grade is $\mathrm{C} 40$, $\mathrm{fc}=14.3 \mathrm{MPa}, \mathrm{ft}=1.43 \mathrm{MPa}, \mathrm{Ec}=32.5 \mathrm{GPa}$. Prestressed steels which are configured in flat beam of frameworks are $2 \varphi^{\mathrm{s}} 15.2$. Framework $1(\mathrm{PPCF}-1)$ adopts bonded prestressed concrete form while framework 2 (UPPCF-1) adopts unbounded one. The shape of prestressed steel is made of by 3 conjoint smooth curves. Also, prestressed strength of frameworks both are 0.67. Geometric dimensioning and reinforcement are shown as Fig.1.

Testing program. In this pseudo-dynamic test, these frameworks are simplified as two single degree of freedom (SDOF) systems with lump mass at each floor height. Based on the ratio of similitude, mass of each floor is $150 \mathrm{KN}$. Horizontal load is acted by electro-hydraulic servo actuator which is 50tons and produced by American MTS Company. Vertical load N is applied on the top of column. Axle load ratio of two beams both are 0.3 . Three-division point force $\mathrm{P}, 20 \mathrm{KN}$, is employed on the beam and keep on vertical load, and then horizontal repeated loads are applied on the end of beams. Here is the loading device in Figure. 2

El-centro earthquake wave, which is adopted in this experiment, is reformed as experimental wave through time compression and amplitude adjustment. Take top 1000 points of original El-centro earthquake wave as input and duration of condensed input wave is 6 seconds.

As experiment begin, firstly test in which horizontal load is acted on the center of beam section height is carried out to achieve structural stiffness, so as to provide necessary information for analysis and calculation; secondly dynamic-loading test in horizontal direction is conducted to obtain period, frequency and damping of framework structures; finally it comes to pseudo-dynamic experiment, in which acceleration peaks of seismic wave $0.05 \mathrm{~g}, 0.1 \mathrm{~g}, 0.2 \mathrm{~g}, 0.4 \mathrm{~g}, 0.8 \mathrm{~g}, 1.2 \mathrm{~g}, 1.6 \mathrm{~g}$, 
$2.4 \mathrm{~g}, 4.0 \mathrm{~g}$ are input in turn to get test-pieces information of cracks and deformation in whole loading procedure, as well as responses magnitude, deformation accumulation, energy dissipating and stiffness deterioration caused by different seismic wave inputs. Figure 2 displays full view of experiment.

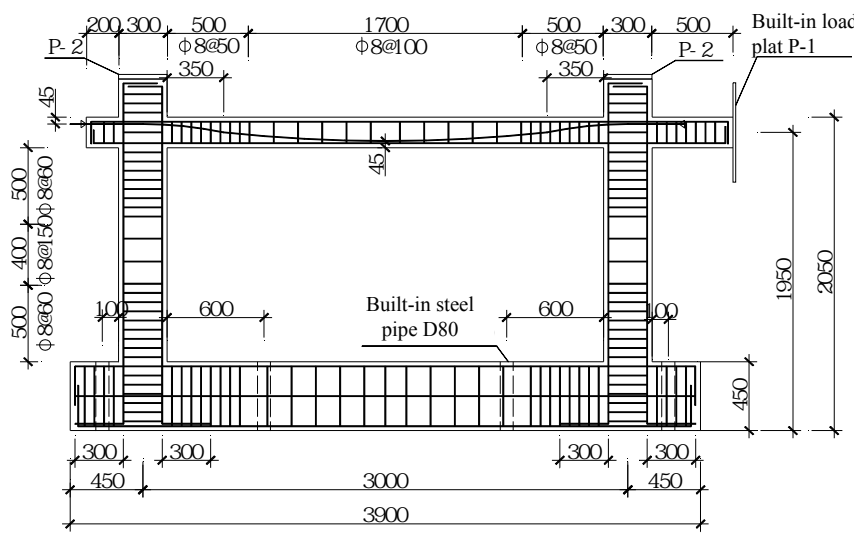

Fig.1 Geometric dimensioning and reinforcement of prestressed flat beam

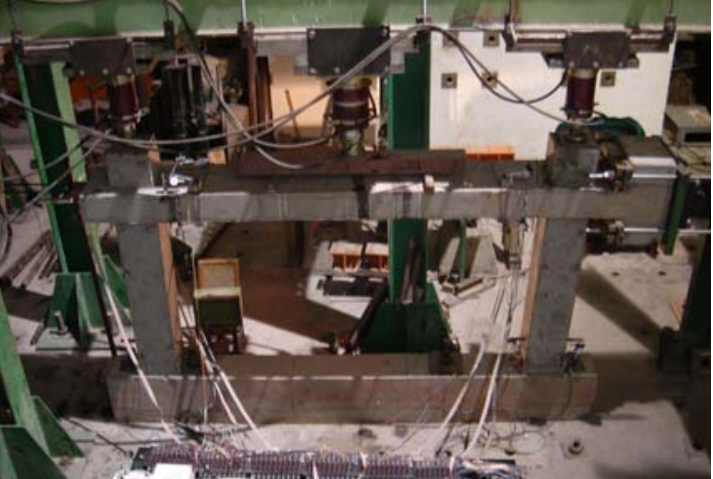

Fig.2 Full view of experiment

\section{Experimental Result and Analysis}

Testing phenomenon. In working condition that acceleration peaks $\left(\mathrm{a}_{\max }\right)$ are $0.05 \mathrm{~g}$ and $0.1 \mathrm{~g}$, testing-pieces basically remain in elastic stage without any crack performance. In working condition that acceleration peaks are $0.2 \mathrm{~g}$ and $0.4 \mathrm{~g}$, small fractures appear in column heel and end of beams gradually. When $\mathrm{a}_{\max }$ comes to $0.8 \mathrm{~g}$, experimental monitoring data show that part of steels in column feet get buckling. When $\mathrm{a}_{\max }$ arrive at $1.2 \mathrm{~g}$ and $1.6 \mathrm{~g}$, cracks are getting through and boarder, lateral displacements are highly obvious in the phase of acceleration peak value. According to monitoring data, testing-pieces are under the ultimate load in working condition that $\mathrm{a}_{\max }$ is $2.4 \mathrm{~g}$, structural damages are increasing and load capacity step into descent stage. In situation that $a_{\max }$ is $4.0 \mathrm{~g}$, frameworks suffer severe structural damage, then stop the test halfway. Experimental results present that cracks developing and failure case of these two samples are approximately the same. In further explanation, column foot and beam ends both are weak as cracks appearance and development, as well as structural final damages happen in these field. Though these testing-pieces are designed in principle of 'strong column and weak beam', it can be seen from final failure form that severe damages appear in column feet. As plastic hinges are founded both in beam ends and column feet, it is actually not an ideal damage form.

Structural stiffness. Stiffness variations are shown in figure 3. Trail result indicates that their stiffness values are basically the same and keep constant in elastic stage. With the rising of earthquake wave input, structural damages increase and result in stiffness deterioration. In prime of plastic stage, PPCF-1 has inconspicuous performance on stiffness deterioration, while UPPCF-1 performs obviously. In later stage, stiffness of PPCF-1 deteriorates dramatically because of serious partial damage and it is less than that of UPPCF-1. Nevertheless, owing to the fact that prestressed steels are only arranged in flat beams, it is insignificant for the whole frame characters so that stiffness difference between these two beams is not particularly apparent.

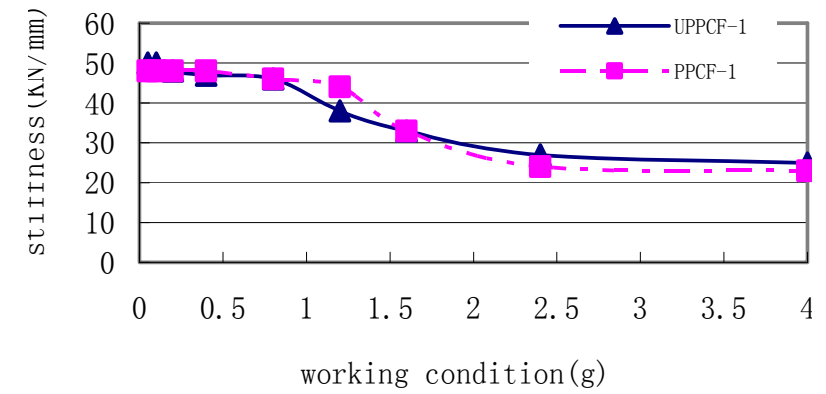

Fig.3 Stiffness variation

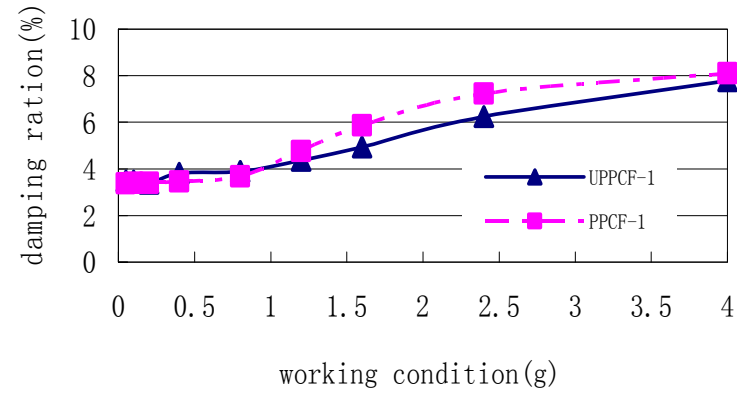

Fig.4 Damping ratio variation 
Structural damping ratio. Considering that damping properties will change with structural damage, dynamic-load test method is employed for measurement. Damping ratio variation are shown in figure 3. The result shows that damping ratios of these two testing-pieces magnify with the increasing acceleration peak of seismic wave, which is resulted from damage accumulation. There is little difference between these two test samples mainly on account of various facts that make influence on framework damping ratio but not only depending on a simple element.

Acceleration response. Select three typical working conditions for analysis of acceleration responses, displacement responses and restoring force property. Case1: acceleration peak value is $0.1 \mathrm{~g}$ which represents elastic stage; case 2 : acceleration peak value is $0.8 \mathrm{~g}$ which means yield stage; acceleration peak value is $2.4 \mathrm{~g}$ which stands for stage of ultimate load.

As shown in figure 5, the peak values of acceleration time-history responses and seismic input wave cannot reach synchronously, also peak points in time-history curve of these two test samples appear in different moment. It is primarily caused by diversity between structural natural period and input wave period, as structural damage accumulating and stiffness descent, structural dynamic properties change a lot so that acceleration responses vary. It is found that these two samples have no significant difference based on comparison of their acceleration time-history curve.

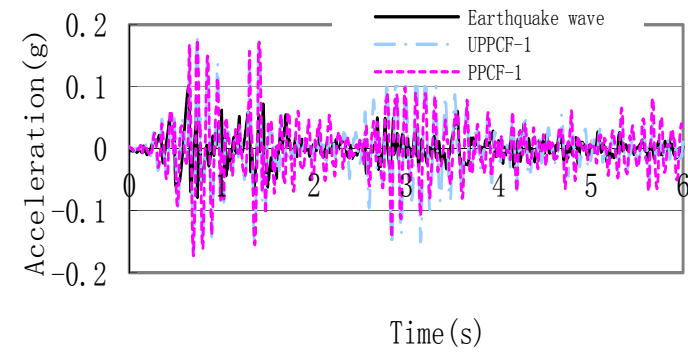

(a) $\mathrm{a}_{\max }=0.1 \mathrm{~g}$

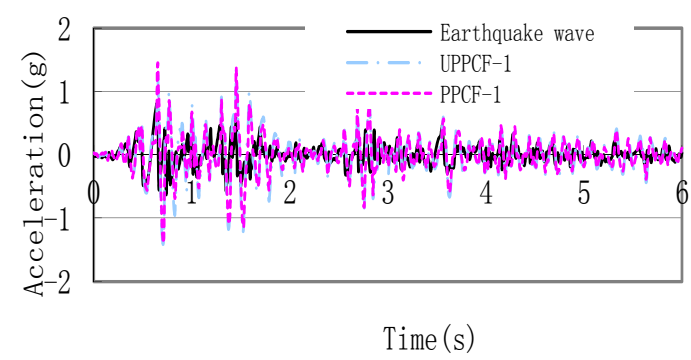

(b) $\mathrm{a}_{\max }=0.8 \mathrm{~g}$

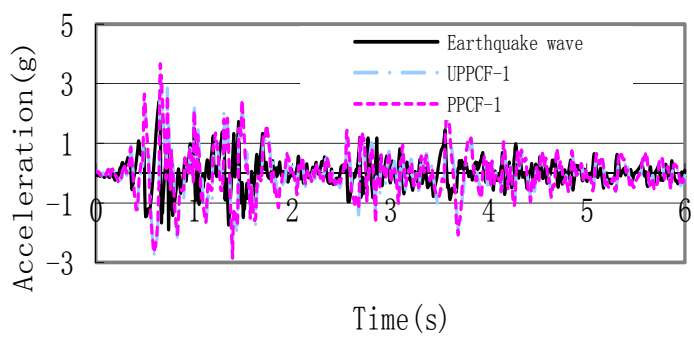

(c) $\mathrm{a}_{\max }=2.4 \mathrm{~g}$

Fig.5 Acceleration responses

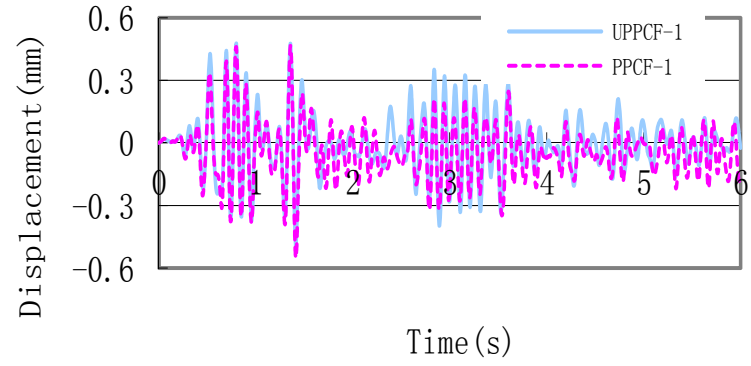

(a) $\mathrm{a}_{\max }=0.1 \mathrm{~g}$

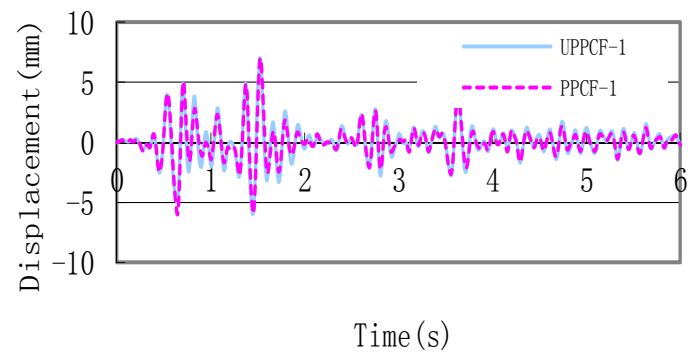

(b) $\mathrm{a}_{\max }=0.8 \mathrm{~g}$

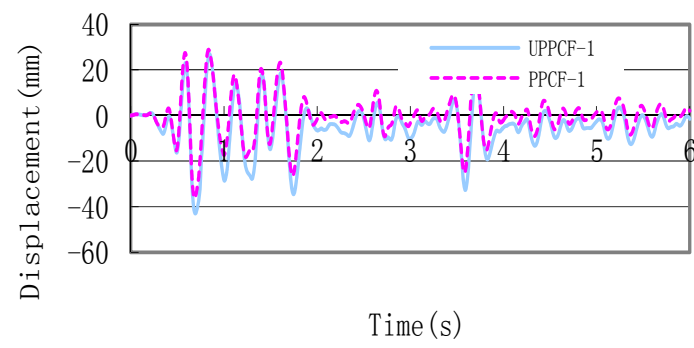

(c) $\mathrm{a}_{\max }=2.4 \mathrm{~g}$

Fig.6 Displacement responses

Displacement response. As drawn in figure 6 the peak values of displacement time-history responses and seismic input wave cannot be at the same time, furthermore displacement responses vary apparently with structural cumulative damage and stiffness deterioration. In the time of 2 to 4 second, displacement responses of structure present clear crest when smaller seismic wave input. After yielding however, amplitudes of peak reduce severely even several ones disappear. Dissimilarities are not apparent when comparing displacement responses of these two samples. But while $\mathrm{a}_{\max }$ arrive at $4.0 \mathrm{~g}$, displacement of PPCF-1 is suddenly larger than that of UPPCF- 1 . The main reason is that stiffness of bonded testing-pieces with partial critical damages reduces more evidently, while unbounded one has better recovering capacity and less displacement response. 
Restoring force property. Load-horizontal displacement curve are measured and portrayed in figure 7.In case1, restoring force curves of these two beams are basically straight lines which demonstrates that frames still stay in elastic stage. In case 2 , their curves become plump and show pinch effect because of concrete cracks in beams ends and column feet steels yielding in column feet region. It also means that plastic stage starts on. Restoring force curves are plumper in case3, looking like reversed S shape. Steels in beam ends and column heel have all yielded and column feet concrete are destroyed by crush. It is easily investigated from figure 6 that framework with prestressed concrete flat beam has proper ability of energy dissipating; Their differences are not evident due to the fact that prestressed reinforcements are only set in flat beam and have little impact on overall performance of energy dissipating.

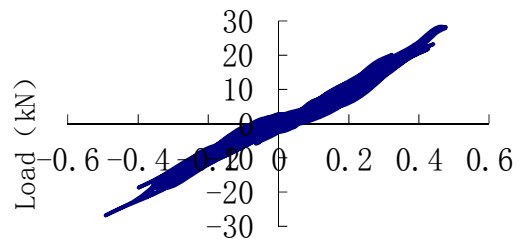

Displacement $(\mathrm{mm})$

(a) UPPCF-1-0.1g

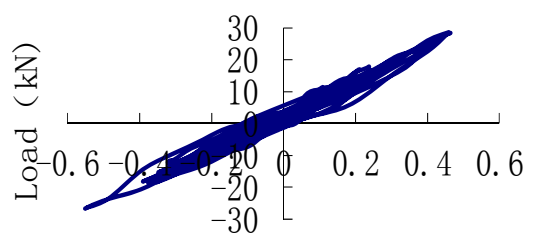

Displacement $(\mathrm{mm})$

(d) PPCF-1-0.1g

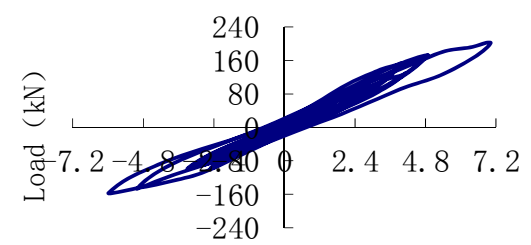

Displacement $(\mathrm{mm})$

(b) UPPCF-1-0.8g

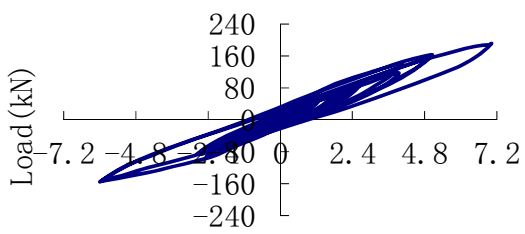

Displacement (mm)

(e) PPCF-1-0.8g

Fig.7 Restoring force curves

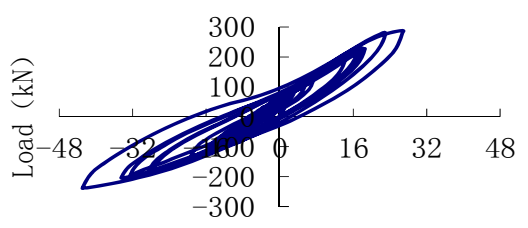

Displacement (mm)

(c) UPPCF-1-2.4g

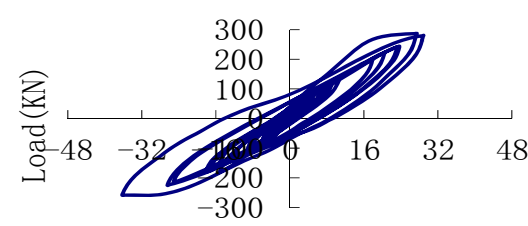

Displacement (mm)

(f) PPCF-1-2.4g

\section{Conclusion}

1) In pseudo-dynamic experiment, the whole stiffness and damping ratio of framework structures are varying caused by damage accumulation; which further results in changing of natural period and affects various structural responses in earthquake finally.

2) Framework with prestressed concrete flat beam has certain capacity of energy dissipating. There are few obvious distinctions between framework with unbonded prestressed concrete flat beam and the other with bonded form.

3) When prestressed steels are reinforced in flat beam, it is impossible to shape ideal failure form if framework is designed on the basis of 'strong column and weak beam', hence proper advancement on beam-column strength ratio should be done.

\section{Reference}

[1] Zhenzheng Fang: Theory and Application of Prestressed Structure [M].Beijing:China Architeture \& Building Press ,2005:198-200.

[2] GB50011-2002,Code for Seismic Design of Building[S].Beijing: China Architeture \& Building Press, 2002.

[3] GB50010-2002. Code for Design of Concrete Structures [S]. Beijing:China Architeture \& Building Press,2002.

[4] Fawei Qiu: Seismic Test Method of Structure[M].Peking:Science Press, 2000.

[5] Shizhu Tian, Tong Zhao: Research of Seismic Pseudo-dynamic Test [J].World Information on Earthquake Engineering.2001. 